\title{
Deviations in Online Communications in the Sphere of Youth Education
}

\author{
Yulia Zubok $^{1, *}$, Elena Chankova $^{2}$, and Oleg Sorokin ${ }^{1}$ \\ ${ }^{1}$ Peoples' Friendship University of Russia (RUDN University), 117198, Moscow, Russia \\ ${ }^{2}$ Plekhanov Russian University of Economics, 117997, Moscow, Russia
}

\begin{abstract}
The transition of the Russian education system in the context of the Covid-19 pandemic to online platforms marked the emergence of new practices of interpersonal communication in the teacher-student relationship system. The article deals with deviant manifestations in the online space of communications. The analysis is based on the study of semantic deviations constructed by young people in the process of communication in a changing reality. The starting point of deviations is considered as a departure from the approved norms of communication in educational system, which leads to such phenomena as trolling, gaming, etc. The influence of virtualization of education on the rethinking of the norms and practices of communication by young people is considered, and the educational space itself, due to its greater openness, becomes a platform for the implementation of these deviant practices. Analysis of the data obtained during sociological research shows the nature of the differentiation of meanings in the field of online communication of young people, which is reflected in the education system.
\end{abstract}

\section{Introduction}

The main function of education as a social institution is the transmission of cultural heritage to a new generation, which creates the basis for the socio-cultural reproduction of society. This means that the communicative activity of the participants in the educational process is an essential part and an important condition for the realization of its social goals. The interaction of participants in the learning process takes place in the educational space, which is "...a kind of space that encompasses a person and the environment during their interaction, the result of which is an augment of the learner's individual culture " [1-11]. This interaction does not arise by chance, but it "... is born in the process of interaction of the subject with the cultural environment due to specially organized activities " [6]. "A person who is living in an object- and event-filled environment forms its subjective image, which is space, and its characteristics reflect the individual peculiarities of the subject's activity interaction with reality" [6]. Communication is a necessary component of education, and the subjective image of the world with its cultural meanings and the reproduction of this world in objective reality will depend on the characteristics of an individual interaction during his education. If the cultural meanings of the subjective image

*Corresponding author: uzubok@mail.ru 
of the world, which is revealed through its values, images of the life world, behavioral attitudes, habits, cultural stereotypes correspond to and are implemented in values, norms, and methods of communication, then the basis for trust in the emerging image of one's social reality is created.

The total nature of rapidly changing modern communications directly affects the nature and outcome of education. Young people are immersed in the conditions of constantly complicated IT, increasing digitalization, which changes not only the forms, but also the meanings of communication. The pandemic of 2020-2021 has created an unprecedented leap in digitalization, primarily by changing the characteristics of the educational space and the ways of communication in it. The younger generation has become a participant in a long period of distance education with the absolute dominance of virtual ways of interaction. Virtual reality in its immanent essence is "... any substitution of reality by its simulation / image - not necessarily with the help of computer technology, but necessarily with the use of the logic of virtual reality" [13]. This creates the basis for the formation of virtual reality communicative space and "... can be defined as an artificially created environment of interactions carried out through network" [15]. Such a transformation in communication, on the one hand, creates a precondition for new communication opportunities, and on the other it creates controversy based on multidirectional cultural norms, values, ideas and expectations of the interaction participants. This controversy is expressed in the clash of cultural meanings and forms of interaction. The simulative nature of virtual communications creates a threat of gaps in interactions, leads to the weakening of communication bonds as the basis of the educational space, creates preconditions for the distortion of cultural meanings that determine the image of the world in the social reality of students.

These circumstances and problems of communication, as well as in education, form a new view of the phenomenon of communicative competence of the individual in the context of changing social reality. In the most general form social reality is understood as the ability of the individual to preserve sociality and social bonds through mobile values, the construction of a flexible individual socio-cultural norm of communication, variable behaviors, adaptive interaction skills. Now there are new requirements to the communicative competence of students engaged in distance education for their effective interaction in the educational process. New requirements are associated with the need to increase adaptability in rapidly changing conditions, flexibility in resolving contradictions that arise in the interaction of different socio-cultural environments representatives, rapid reflection of the communicative situation "here and now", the choice of the optimal mode of communication in an open online space. All of that points to the self-regulating nature of the communicative processes of the youth. In other words, young people build their own communication interactions.

In the virtual environment in which distance learning takes place this process is ambiguous. It has a simulative component typical of this environment, social control is reduced, institutional regulatory function is weakened, all the above increases the likelihood of destruction of communication and the appearance of deviant forms of it. The youth's own communicative competence becomes the only regulator. It turns out to be the factor that can cope with the resulting destructions. Due to self-regulation and self-construction the communicative competence of the individual in the modern digital conditions of education becomes the driving force for overcoming the emerging deviations and gaps in communication and for the formation of new meanings and practices in the educational space in the conditions of online learning.

The youth's practices of online communication bear the "generic properties" of the cultural space in which young people are included. As a part of society and as a specific socio-demographic group, they are influenced by samples of both general culture and youth 
subcultures and assimilates them. That is why both new communication norms and deviations will be a projection of these types of culture. Therefore, the emergence of new communication phenomena is important for the analysis of deviations in the communications of young people and the construction of new meanings. So, in the modern Russian blogging, in particular in socio-political social discourse, $[4,8,10]$ there is often a gamification- a hybrid of the gaming and pragmatic action. The most self-confident actors perceive the situation as a game, replacing its essence, and strive to realize themselves in the game space most profitably through a reflexive search and foresight of various options. Actors preserve and even increase the degree of uncertainty of the situation by distorting its meanings, turn interaction into a game, and strive to win by any means. According to Li K., Lin Z., Wang X. " ... the participants seek to hurt each other, not to prove the truth, but to make a fool of their interlocutor in front of others. This is the social behavior of a person on the Web" [10]. The educational space is no exception. In this case it does not differ much from other virtual platforms where participants practice hating.

The virtual environment has its own effect of "curved mirrors" in interaction - it happens because of the loss of "lenses" which are socio-cultural regulators. This effect is called "aberration" (changes in the direction of light and information when moving from one frame of reference to another) [1] and it is common in political communications. "...The main task of show-policy is to simulate reality, create virtual imitation, an analogue of political reality. At the core of political discourse today there is the dominant figure, the mediator-trickster, who plays a custom-made performance in the genre of show in politics " [1]. Performance can be quite transparently read as a virtual means of communication, which contains, on the one hand, an unwillingness to retain the primary meanings of interaction participants, on the other hand a distortion of reality, a demonstration of the conventionality of what is happening. In education, this happens in the form of trolling - the purposeful destruction of semantic content by groups of young people breaking into online communications.

The tools of trolling that are used today, such as manipulation of public opinion, provocation, thematic shift, violation of logic, and the emergence of doubts about the truth $[7,9]$, point to the actors' ideas about communicative competence in virtuality. As an incentive to achieve a communicative goal in such actions is called "...getting some form of satisfaction from the fact that it is he who at this moment becomes the epicenter of unfolding discussions and confrontations" [12] It should be noted that trolling is considered as a cause (a separate statement), and flaming is already considered as a dialogical interaction, a dispute for the sake of a dispute, as a consequence of effective trolling [7]. The spread of trolling as a form of virtual communication built based on the game: "... trolling is a game of fake identity, but without the consent of the majority of players who are not aware of participating in this game" [7] became a mass phenomenon during the transition to remote forms in the field of education.

From the perspective of compensation theory [3], gamification, performance, gamification, trolling, and flaming are the means of simplifying the increasingly complex social structure of life. The social consequence of this kind of games can become a demand, for example, for trolling without undesirable social consequences in conditions of anonymity. This deviation is based on the unstructured ethics of network communication and the destruction of normativity as a characteristic of the cultural space of young people, when aggressive and offensive trolling behavior becomes attractive, leads participants away from the social meaning of interaction and is presented as communicatively competent, leading to the desired social results.

The use of forms, that distort communication and admit the possibility of deviations and their transfer to the online space of education, by young people is determined by semantic 
transformations and changes in the attitude of young people to what is permissible and not permissible in communication.

\section{Materials and methods}

Let us look at how the communicative competence of Moscow universities students manifests itself (the survey was conducted in Google format in the fall of 2020 as part of the sociological study "Self-regulation of the life of young people in a changing social reality" of the ISPI FCTAS RAS, N=100, sample was "snowball"). The research methodology is based on the concept of socio-cultural mechanisms of reproduction of social reality [14], the concept of virtual reality [2], and educational space [5-6, 11].

In 2020, the Center for Youth Sociology of the ISPI of the Russian Academy of Sciences conducted a study on deviant meanings in the cultural space of Russian youth. The field research was conducted in June-September 2020 by the Center for Youth Sociology of the ISPI RAS together with the Institute of Public Opinion Qualitas in the form of a questionnaire. A total of 1,110 respondents aged 15 to 35 years from 11 subjects of the Russian Federation were interviewed. Trolling in the study was considered as a deviation, i.e. a digression from the reference sample. In the system of teacher - student relations, the norm is a model of interaction based on mutual respect, recognition of the interests of the participants who enter communication.

\section{Results}

The features of communicative competence for two types of socio-cultural environments interpersonal interaction (real) and interaction based on Internet platforms (virtual), were being identified. The following empirical indicators were measured: values, norms, skills, ways of behavior, images of the life world in the communicative competence of the individual. It should be noted that the survey was conducted in the conditions of remote and partially remote education, and of quarantine restrictions because of Covid-19. There is no doubt that the respondents ' presence in a virtual socio-cultural environment left a mark on the state of their social reality, their ideas about communication at the time of the survey, and it can be assumed that students have transferred the updated socio-cultural meanings of communication to their behavior in the educational process.

In the image of the life world of the respondents, communication is associated with maintaining contacts with many acquaintances (38.6\%) and with friendship, permanent relationships (29.55). Minority (6.8\%) of respondents associates non-binding contacts with communication. It means that there is a tendency to constancy, retention of connections. The lack of commitment, which weakens social bonds, is supported by a minority. Within such ideas about communication, $79.6 \%$ of respondents consider themselves successful and quite successful in communication, in other words their successful communication takes place in conditions of maintaining and fulfilling obligations. Low self-esteem in communication was indicated by $6,8 \%$ of the respondents. Taking that into consideration the percentage of respondents who have fulfilled their expectations from communication is logical - fully-a fifth, $22.7 \%$, and rather completely- $60.2 \%$, not implemented $-2.3 \%$. We see a fairly good overall picture of the state of communication among students.

However, $60.2 \%$ of respondents seek to exchange meanings and understand the other in real interactions and in virtuality this percentage decreases to $34.1 \%$ - almost twice. A similar distribution is maintained in the desire for trustful interaction $-64.8 \%$ in reality and $31.8 \%$ in virtuality. So, virtuality is not considered by respondents as a communicative space for the exchange of meanings, understanding and trust. At the same time, these 
categories are the key ones for revealing the essence of interaction. It can be concluded that there are significant value changes in the structure of communicative competence in virtuality in comparison with interpersonal real contacts.

The urge for hype is supported by an equal number of respondents for both real and virtual contacts - 33\%. Probably, this can be explained by the general feature of young people as a socio-demographic group that has a positive general tone of life, regardless of the socio-cultural capabilities of the environment, which is also manifested in communicative competence.

In real communications $62.5 \%$ agree and $36.4 \%$ rather agree, for virtual ones $-54.5 \%$ agree and $44.3 \%$ rather agree with the statement "Modern life requires changes to the established rules, if they are agreed with others". Such similar distribution for different environments is also explained by the features of young people as carriers of an innovative type of culture [14], and not by the similarity of the types of communicative competence in different socio-cultural environments.

The answers to the question of what qualities the respondents show in real and network communication were distributed for interpersonal and network relations respectively: honesty $(92.96 \%$ and $7.04 \%)$, conscientiousness $(81.7 \%$ and $18.3 \%)$, sincerity $(84.2 \%$ and $15.8 \%$ ), cunning $(21,3 \%$ and $79.7 \%)$, responsibility $(87,5 \%$ and $12.5 \%)$, unreliability $(17.3 \%$ and $72.6 \%)$, a sense of brotherhood $(67,3 \%$ and $32.7 \%)$. We see a strong difference between traditional and modern manifestations of personal qualities in the interaction in reality and virtuality. If we correlate these distributions with the respondents ' ideas about communication (the value of friendship, maintaining contacts with acquaintances), then these differences are more instrumental than terminal, and do not affect the deep foundations of personality.

The changes in the nature of the ability to communicate in a virtual environment compared to real interpersonal communication (listening skills - 89 and $11 \%$ respectively, observing the rules of polite communication -78 and $22 \%$, maintaining good relations 84.2 and 15.8) indicates a distortion of the essential characteristics of online communication activities.

Conclusion about the ambiguous nature of changes in the socio-cultural regulators of communication - in values, norms, skills, and behavior can made. These changes can be considered as instrumental ones, but they cause substantive distortions in communication and initiate destructions. The analysis of communication processes in various spheres indicates their instrumentalization in the conditions of virtuality.

Young people who use trolling practices in online communications violate the basic principles of the ethics of interpersonal relations, invading the personal space of an individual, provoking him to conflict behavior, insulting him. In online communications of the "professor-student", "teacher-student" relationship system, the purpose of trolling in relation to teachers is an attempt to assert themselves, draw attention to themselves, belittle the role of the teacher in the educational process, demonstrate his professional incompetence, for example, in the field of information technology. Most of so-called zoom, Skype, teams-trolls who began to break into online conferences during the pandemic did it either for entertainment or for the purpose of further monetization of their content, i.e. posted records of trolling, teachers, etc., so-called "raids" on video hosting sites to increase their audience and the number of views. For many initiators and participants of such actions, provocative communication practices are not considered as a deviation from the ethical norms of interpersonal relations, moreover, from their point of view, these practices are designed to level the status differences between the teacher and the student, to identify ineffective teachers who cannot manage the communication processes in the network. The troll will quickly stop the practice of publicly ostracizing the teacher as soon as the teacher identifies him and stops responding to his provocations. 


\section{Discussion}

In the system of teacher - student relations, the norm is a model of interaction based on mutual respect, recognition of the interests of the participants who enter into communication. Young people who use trolling practices in online communications violate the basic principles of the ethics of interpersonal relations, invading the personal space of an individual, provoking him to conflict behavior, insulting him. In online communications of the "professor-student", "teacher-student" relationship system, the purpose of trolling in relation to teachers is an attempt to assert themselves, draw attention to themselves, belittle the role of the teacher in the educational process, demonstrate his professional incompetence, for example, in the field of information technology. Most of so-called zoom, Skype, teams-trolls who began to break into online conferences during the pandemic did it either for entertainment or for the purpose of further monetization of their content, i.e. posted records of trolling, teachers, etc., so-called "raids" on video hosting sites to increase their audience and the number of views. For many initiators and participants of such actions, provocative communication practices are not considered as a deviation from the ethical norms of interpersonal relations, moreover, from their point of view, these practices are designed to level the status differences between the teacher and the student, to identify ineffective teachers who cannot manage the communication processes in the network. The troll will quickly stop the practice of publicly ostracizing the teacher as soon as the teacher identifies him and stops responding to his provocations.

The purpose of the research about trolling was to study the deviant meanings of social processes in the context of changing social reality in the youth environment. Agreeing with the statement that trolling today is the norm of communication means that a young person considers trolling practices as acceptable in online communications, including communication between a teacher and a student. During the study respondents were asked to express their agreement/disagreement with the following statement: "Trolling" is the norm of communication, trolling is acceptable". Agreement with the statement was interpreted as acceptance of the deviant meaning, and disagreement was interpreted as adherence to normative ethics in interpersonal communication. The attitude of Russian youth to this statement, which contains a semantic deviation, is presented in Table 1.

Table 1. Attitude to trolling among the youth.

\begin{tabular}{|c|c|c|}
\hline $\begin{array}{c}\text { To what extent do you agree } \\
\text { with the statement: "Trolling" } \\
\text { is the norm of } \\
\text { communication, trolling is } \\
\text { acceptable." }\end{array}$ & Quantity of answers & $\%$ \\
\hline Totally agree & 131 & 11.3 \\
\hline Rather agree & 228 & 19.7 \\
\hline Rather disagree & 296 & 25.6 \\
\hline Totally disagree & 500 & 43.3 \\
\hline
\end{tabular}

As it follows from the table most young people do not support the judgment that "Trolling" is the norm of communication, trolling is acceptable" (68.9\% of respondents), which indicates a choice in favor of normative ethical models of communication. At the same time, every third respondent believes that this practice is acceptable, moreover, it acts as a form of communication. In social reality of this group of young people the previous ideas about the standards of acceptable behavior in the communicative space are reinterpreted. In many ways, these processes are associated with an increase in instrumental motivation in relation to communication, when its deviant forms begin to perform the 
function of attracting attention to the person to assert his "ego" through the cult of moral violence against, for example, status figures, or in order to maximize profits by popularizing content with destructive content.

Let us look at how ideas about trolling differ in different groups of young people, depending on the place of study (Table 2).

Table 2. The relation of the place of study to the deviant meaning of interpersonal communication among the youth.

\begin{tabular}{|l|c|c|c|c|}
\hline \multirow{2}{*}{ Place of study } & \multicolumn{4}{|c|}{ Relation to the statement "Trolling" is the norm of communication, } \\
& Agree & Rather agree & Rather disagree & Disagree \\
\cline { 2 - 5 } & $18.0 \%$ & $20.2 \%$ & $36.0 \%$ & $25.8 \%$ \\
\hline $\begin{array}{l}\text { School, } \\
\text { gymnasium }\end{array}$ & $13.2 \%$ & $28.1 \%$ & $28.9 \%$ & $29.8 \%$ \\
\hline $\begin{array}{c}\text { lyceum, technical } \\
\text { school }\end{array}$ & $15.3 \%$ & $22.8 \%$ & $27.5 \%$ & $34.4 \%$ \\
\hline $\begin{array}{c}\text { university, } \\
\text { institute }\end{array}$ & $12.0 \%$ & $13.0 \%$ & $25.0 \%$ & $50.0 \%$ \\
\hline $\begin{array}{c}\text { postgraduate } \\
\text { study, residency }\end{array}$ & & & & \\
\hline
\end{tabular}

The data presented in Table 2 shows that ideas about the trolling in communications being acceptable vary on the place of study. So, while among students of postgraduate study and residency the share of those who agree and rather agree with the statement was $25 \%$, among students at universities and technical schools this share was already $38.1 \%$, among students of lyceums and technical schools - $41.3 \%$, and among students at schools and gymnasiums $-38.2 \%$. Thus, among students of educational organizations of secondary vocational education, as well as among students at schools, lyceums and universities, there is an interest in trolling practices.

Communicative deviations in the online education are differently perceived by young people, depending on their age. (Table3).

Table 3. The relation of the age to the deviant meaning of interpersonal communication among the youth.

\begin{tabular}{|c|c|c|c|c|}
\hline Age & \multicolumn{4}{|c|}{$\begin{array}{c}\text { Relation to the statement "Trolling" is the norm of } \\
\text { communication, trolling is acceptable", } \%\end{array}$} \\
& Agree & Rather agree & $\begin{array}{c}\text { Rather } \\
\text { disagree }\end{array}$ & Disagree \\
\hline & $17.9 \%$ & $24.8 \%$ & $29.7 \%$ & $27.6 \%$ \\
\hline $15-17$ years & $12.5 \%$ & $23.2 \%$ & $27.4 \%$ & $36.9 \%$ \\
\hline $18-24$ years & $8.3 \%$ & $18.7 \%$ & $27.0 \%$ & $46.0 \%$ \\
\hline $25-29$ years & $9.6 \%$ & $13.6 \%$ & $19.9 \%$ & $56.8 \%$ \\
\hline $30-35$ years & & & & \\
\hline
\end{tabular}

The data presented in Table 3 shows that the extent to which respondents agree with the statement "Trolling is the norm of communication, trolling is acceptable" relates to the age of the respondent. In the older age group of young people (30-35 years), the distribution of the values of the analyzed deviating meaning was $23.2 \%$, in the age group of 25-29 years it was already $27 \%$, in the group of $18-24$ years $-35.7 \%$, and among $15-17$ years $-42.7 \%$. The trend of increasing approval of the trolling practice in communication in younger age groups is not accidental. The instrumental attitude to communication as a tool for selfpromotion is explicitly seen specifically in the younger age groups. In addition, for many 
young people aged 15-24 practices based on the provocations of their interlocutor are common since these practices allow to bring an entertaining mood to a serious conversation.

Significant differences are noted depending on the orientation of young people to certain types of culture. Particularly arises in connection with youth attitude to norms and their necessity in the social life. The data analyzed in Table 4 shows the dominant connection between the culture of moral anomie and the deviant meaning "Trolling is the norm of communication, trolling is acceptable" in the social reality of young people $(17.8 \%$ of respondents). This type of culture "symbolizes the rejection of generally shared unconditional norms and their displacement by so-called situational norms that are utilitarian in specific life situations" [15]. The basis of this culture is cynicism, built on the variability of principles. These results allow us to conclude that trolling as a form of communication is accepted in those groups of young people who are trying to rationalize interpersonal communication to adjust them to their own rules.

Table 4. Relation of different types of culture to deviant meaning of interpersonal communication among the youth.

\begin{tabular}{|c|c|}
\hline Type of culture & $\begin{array}{c}\text { Relation to the statement } \\
\text { "Trolling" is the norm of } \\
\text { communication, trolling is } \\
\text { acceptable", \% }\end{array}$ \\
\hline Spiritual culture & 11.9 \\
\hline Culture of innovation & 12.1 \\
\hline Physical development culture & 12.3 \\
\hline Hedonistic culture & 15.4 \\
\hline Culture of adaptation & 15.1 \\
\hline Culture of moral anomie & 17.8 \\
\hline
\end{tabular}

\section{Conclusions}

Thus, the conducted research allowed us to study deviant manifestations in the online communication space. The semantic deviations constructed by young people in the process of communication in a changing reality were examined. In the social reality of young people, innovative and deviant meanings of understanding interpersonal communication in the education system coexist along with the traditional normative standards of interpersonal communication which leads to such phenomena as trolling, gaming, etc. The integration of these meanings into the processes of understanding social reality by young people indicates an increase in the processes of instrumentalization of communication among young people. In addition, the transition to online forms of education contributes to the redesign of the norms of communication among young people and the reduction of the social control function.

The research was carried out within the state assignment of Ministry of Science and Higher Education of the Russian Federation, project number 075-00167-20-03 «Social and humanitarian foundations of countering extremism»

\section{References}

1. S. Akhtar, C. Morrison, The prevalence and impact of online trolling of UK members of parliament. Computers in Human Behavior, 99, 322-327 (2019) DOI:10.1016/j.chb.2019.05.015 
2. M. Castells, Power of the Communication (Higher School of Economics Publishing House, Moscow, 2016).

3. J. Coburn, J. Salmon, I. Freeman, The effects of transition style for collaborative view sharing in immersive virtual reality. Computers \& Graphics, 92, 44-54 (2020) DOI: $10.1016 /$ j.cag.2020.08.003

4. D. F. Rosmala, Study of Social Networking usage in Higher Educational Environment. Procedia-Social and Behavior Sciences, 67, 156-166 (2012) DOI: 10.1016/j.sbspro.2012.11.316

5. I. Frumin, B. Elconin, Educational space as development space. Psychology issues, 1, 24-32 (1993)

6. J. Hill, D. France, Innovative Pedagogies. International Encyclopedia of Human Geography (Second Edition), 331-339 (2020)

7. C. J. Jenks, Talking trolls into existence: On the floor management of trolling in online forums. Journal of Pragmatics, 143, 54-64 (2019) DOI:10.1016/j.pragma.2019.02.006

8. T. Jiang, Y. Hou, Q. Wang, Does microbligging make us "shallow"? Sharing information online interferes with information comprehension. Computers in Human Behavior, 50, 210 - 214 (2016) DOI:10.1016/j.chb.2016.02.008 0747-5632

9. K. Laitinen, M. Valo, Meanings of communication technology in virtual team meetings: Framing technology- related interaction, International Journal of HumanComputer Studies, 111, 12-22 (2018) DOI:10.1016/j.ijhcs.2017.10.012

10. K. Li, Z. Lin, X. Wang, An Empirical analysis users' privacy disclosure behaviors on socialnetwork sites. Information \&Management, 52(7), 882-891 (2015) DOI:10.1016/j.im.2015.07.006

11. J.I. Liontas, The TESOL Enciclopedia of English Language Teaching. Printed in Singapore by C.O.S., Printers Pte Ltd. (2018)

https://books.google.com.do/books?hl=en\&lr=\&id=pppFDwAAQBAJ\&oi=fnd\&pg=P P3\&dq=pedagogical+encyclopedia\&ots=yJkKOm17RJ\&sig=YDLQLDiToN8khzZL8jhkzW450U (last accessed 2021/03/18)

12. E. March, Psychopathy, sadism, empathy, and motivation to cause harm: New evidence confirm malevolent nature of the Internet Trolls. Personality and Individual Differences, 141, 133-137 (2019) DOI:10.1016/j.paid.2019.01.001

13. H. Tomaskova, Z. Nemcova, M. Simkova, Usage of Virtual Communication in University Environment. Procedia-Social and Behavioral Science, 28, 360-364 (2011) DOI: $10.1016 /$ j.sbspro.2011.11.068

14. Y. Zubok, V. Chuprov, Youth in the cultural space: self-regulation of life. Norma. Moscow (2020)

15. Y. Zubok, V. Chuprov, Life-meaning values in the cultural space of Russian youth. Scientific result, 4(3), 3-14 (2018). DOI: 10.18413/2408-9338-2018-4-3-0-1 